\title{
Desafios para educação de qualidade e o direito à aprendizagem de jovens, adultos e idosos no tempo presente: o que pensam os professores?
}

\author{
Challenges for quality education and the right to learning of young people, adults and the elderly \\ at the present time: what do teachers think?
}

Desafíos para una educación de calidad y el derecho al aprendizaje de los jóvenes, adultos y ancianos en la actualidad: ¿qué piensan los docentes?

Carlos Soares Barbosa - Universidade do Estado do Rio de Janeiro | Faculdade de Educação | Rio de Janeiro | RJ | Brasil. E-mail: profcarlossoares@gmail.com | (orсіD

Raquel Lopes Pires - Universidade Federal do Rio de Janeiro | Faculdade de Educação | Rio de Janeiro / RJ / Brasil. E-mail: rlopes.pires@gmail.com | (10) orciD

Resumo: O objetivo desse artigo é analisar, com base na concepção dos professores, as mediações que dificultam a educação de qualidade e a plena garantia do direito à aprendizagem de jovens, adultos e idosos no tempo presente. Trata-se de resultados parciais da pesquisa exploratória, em andamento, que fez uso, até o momento, de entrevistas de roteiros semiestruturados realizadas com 16 professores do Ensino Fundamental e Médio das redes municipal/estadual do Rio de Janeiro, Duque de Caxias e Piraí. Os resultados sinalizam que os desafios para a qualidade da Educação de Jovens e Adultos (EJA) e para as aprendizagens dos sujeitos referem-se aos aspectos das políticas públicas e do cotidiano escolar: a quase ausência de formação docente para atuar na modalidade, currículo pouco apropriado, permanência de práticas pedagógicas pautadas no paradigma da suplência, dificuldade dos professores em trabalhar com a diversidade, intensificada com a juvenilização e com o aumento de estudantes com necessidades educacionais especiais na modalidade.

Palavras-chave: Educação de jovens e adultos. Qualidade da educação. Concepções docentes.

Abstract: The aim of this article is to analyze, based on the teachers' conception, the mediations that hinder the quality education and the full assurance of the right to the learning of young people, adults and the elderly in the present time. These are partial results of the ongoing exploratory research that has, to date, used interviews of semi-structured scripts conducted with 16 primary and secondary school teachers from the munici$\mathrm{pal} / \mathrm{state}$ networks of Rio de Janeiro, Duque de Caxias and Piraí. The results indicate that the challenges for the quality of Youth and Adult Education (EJA) and for the learning of the subjects refer to the aspects of public policies and daily school life: the almost absence of teacher education to work in the modality, little curriculum appropriate, permanence of pedagogical practices based on the paradigm of substitution, difficulty of teachers to work with diversity, intensified with the youth and the increase of students with special educational needs in the modality.

Keywords: Youth and adult education. Quality education. Teaching conceptions.

- Recebido em 29 de março de 2019 • Aprovado em 19 de setembro de 2019 • e-ISSN: 2177-5796

DOI: http://dx.doi.org/10.22483/2177-5796.2020v22n1p271-291

Copyright @ 2019. Conteúdo de acesso aberto, distribuído sob os termos da Licença Internaonal da CreativeCommons - CC BY-NC-SA - Atribuição Não Comercial (https://br.creativecommons.org/licencas/) - Permite distribuição e reprodução, desde que atribuam os devido créditos à publicação, ao autor(es) e que licenciem as novas criações sob termos idênticos. 
BARBOSA, Carlos Soares; PIRES, Raquel Lopes. Desafios para educação de qualidade e o direito à aprendizagem de jovens, adultos e idosos no tempo presente: o que pensam os professores?

Resumen: El objetivo de este artículo es analizar, a partir de la concepción de los docentes, las mediaciones que obstaculizan la educación de calidad y la plena garantía del derecho al aprendizaje de los jóvenes, adultos y personas mayores en la actualidad. Estos son resultados parciales de la investigación exploratoria en curso que, hasta la fecha, ha utilizado entrevistas de guiones semiestructurados realizadas con 16 profesores de escuelas primarias y secundarias de las redes municipales/estatales de Río de Janeiro, Duque de Caxias y Piraí. Los resultados indican que los desafíos para la calidad de la Educación de Jóvenes y Adultos (EJA) y para el aprendizaje de las asignaturas se refieren a los aspectos de las políticas públicas y de la vida escolar cotidiana: la casi ausencia de formación docente para trabajar en la modalidad, la escasa adecuación curricular, la permanencia de prácticas pedagógicas basadas en el paradigma de la sustitución, la dificultad de los docentes para trabajar con diversidad, la intensificación de la colaboración con los jóvenes y el aumento de estudiantes con necesidades educativas especiales en la modalidad.

Palabras clave: Educación de jóvenes y adultos. Calidad de la educación. Concepciones de los maestros. 


\section{Introdução}

Conceitualmente, a Educação de Jovens e Adultos (EJA) considera todo o processo de aprendizagem, formal ou informal, que vivenciam pessoas jovens, adultas e idosas ao longo da vida. Essa concepção ampliada de EJA, consolidada desde a V Conferência Internacional da Educação de Adultos (CONFINTEA), ocorrida em 1997 na cidade de Hamburgo, na Alemanha, entende que a escola não é o único local de construção do conhecimento, mas um entre muitos espaços sociais de formação humana. Consequentemente impõe a necessidade de reconhecer as múltiplas experiências de aprendizados vivenciados pelos sujeitos ao longo da vida, uma vez que são por meio dessas experiências que eles se humanizam e ativamente fazem a construção do/sobre/com o mundo. Ainda segundo o referido documento, significa dar às pessoas, independentemente da idade, a oportunidade de desenvolver seu potencial, coletiva ou individualmente, sendo para isso "fundamental que o reconhecimento do direito à educação continuada durante a vida seja acompanhado de medidas que garantam condições necessárias para o exercício desse direito" (UNESCO, 1997).

Em específico a vertente escolar, a EJA é concebida como modalidade da educação básica e, por assim ser, possui especificidades próprias que demandam organização curricular, recursos pedagógicos, metodologias, formação docente e políticas públicas que atendam a esse outro modo de ser da educação básica. No entanto, as políticas públicas não têm sido capazes de assegurar as condições básicas para a escolarização com êxito de jovens, adultos e idosos, o que faz com que a EJA permaneça emaranhada em uma rede de desqualificações (VENTURA; RUMMERT, 2011), visto que a problemática e a riqueza potencial da modalidade continuam, em geral, ignoradas ou relegadas ao plano secundário pela maioria dos gestores e das redes públicas de ensino do país. Decorre desse processo, segundo as autoras, a construção/execução de projetos pedagógicos pobres, sem muito rigor metodológico e conceitual, destinados a pessoas pobres, já que o público atendido na EJA é constituído, majoritariamente, por pessoas que têm em comum a marca da pobreza; moradores das periferias urbanas e áreas rurais que presenciam em seu cotidiano a violação dos direitos humanos básicos, como segurança pública e a oferta de saúde e educação públicas de qualidade. 
Paiva (2014) identifica dois grandes desafios à EJA no tempo presente: o reconhecimento da educação como direito social e fundamental da pessoa humana, cabendo ao Estado o dever de ofertá-la em condições satisfatórias; e o direito de aprender por toda a vida. De acordo com a autora, o desafio consiste em garantir a justiça social a sujeitos jovens e adultos interditados da escola na infância, ou que nela não tiveram sucesso porque descriminados nos processos de conhecimentos.

Entender a dinâmica interna da modalidade por meio das narrativas dos professores possibilita-nos compreender como agem/resistem diante do descompromisso político de gestores públicos com a educação de qualidade ofertada as camadas pobres da população, o que elide na permanência em pleno século XXI do analfabetismo e a não universalização da educação básica. O crescimento econômico ocorrido nos governos Lula da Silva (2003-2010) não foi capaz de reverter à dívida histórica para com milhares de brasileiros e alterar significativamente essa triste realidade educacional. Ainda que tenha ocorrido relativa melhoria nos índices educacionais no período mencionado, conforme indicam os resultados do último Censo Demográfico, quando a taxa de analfabetismo da população acima de 15 anos de idade caiu de 13,6\%, no ano 2000, para 9,6\%, em 2010, é preciso considerar que ainda existem em torno de 11,5 milhões de brasileiros analfabetos com 15 anos de idade ou mais, conforme os dados da Pesquisa Nacional por Amostra de Domicílios Contínua (Pnad), referente ao ano de 2017 (IBGE, 2018).

O quantitativo aumenta para 38 milhões de jovens e adultos, de 15 a 64 anos, quando se considera os chamados analfabetos funcionais, isto é, pessoas com níveis de aprendizagens abaixo dos mínimos socialmente necessários em tarefas cotidianas de leitura, escrita e cálculo para que possam manter e desenvolver as competências características do alfabetismo. Os dados revelam que a passagem pelo sistema de ensino não tem garantido a um grupo considerável de pessoas a consolidação de uma aprendizagem autônoma para seu cotidiano, não obstante os dados da mesma Pnad demonstrem que aumentou a proporção de pessoas de 25 anos ou mais de idade que concluíram o Ensino Médio, de 45,0\%, em 2016, para 46,1\%, em 2017.

De certo, os programas de aceleração e reposição de estudos implementados pelos gestores municipal, estadual e federal destinados aos estudantes do Ensino Fundamental e Médio em defasagem idade-série contribuíram para o aumento da escolaridade da população jovem de 15 a 29 anos, como, por exemplo, o Programa Autonomia, executado na rede estadual de educação do 
Rio de Janeiro em pareceria com o Instituto Ayrton Senna, no período de 2009-2016, e o programa federal Projovem Urbano, executado em várias cidades brasileiras no período de 2005-2016. Mas com qual qualidade? Entendendo que qualidade na EJA implica dar aos estudantes "oportunidade de desenvolver potencialidades e a capacidade de ser sujeito de sua própria ação" (PAIVA, 2014, p. 91).

Feitas essas considerações iniciais, o objetivo do presente texto é analisar, na concepção dos professores, as mediações que dificultam a educação de qualidade e a plena garantia do direito à aprendizagem de jovens, adultos e idosos no tempo presente. Trata-se de reflexões tecidas com base na análise de dados da pesquisa qualitativa iniciada em 2018 e ainda em andamento. A premissa que tem orientado o estudo é a de que a EJA escolar precisa ser entendida por meio da sua rotina diária, dando voz aos seus principais atores - estudantes, professores e gestores escolares. Privilegia-se neste texto as vozes dos docentes.

Quanto ao percurso metodológico, trata-se de estudo exploratório, que constituiu a formação docente, os aspectos curriculares, a prática pedagógica e a marginalização da EJA no âmbito das políticas públicas como hipóteses iniciais para compreender os desafios para a educação de qualidade e o direito à aprendizagem de jovens, adultos e idosos no tempo presente. Até o momento foram realizadas entrevistas com roteiros semiestruturados a 16 docentes, que aceitaram participar de forma voluntária à pesquisa após consulta inicial feita por e-mail a 35 professores da EJA de diferentes redes públicas de ensino do estado do Rio de Janeiro. Do total de professores entrevistados, duas são dos anos iniciais do Ensino Fundamental e atuam na rede municipal de Duque de Caxias (município situado na região da Baixada Fluminense do Rio de Janeiro); cinco são professores dos anos finais do Ensino Fundamental (quatro atuam na capital do Rio de Janeiro e uma na rede municipal de Piraí, região sul fluminense), e nove lecionam no Ensino Médio, na rede estadual de educação do Rio de Janeiro. O texto preserva o anonimato dos participantes, identificando as professoras do Ensino Fundamental I como Professoras A e B; os do Ensino Fundamental II utilizando as letras do alfabeto de C a G; e os do Ensino Médio professores de $\mathrm{H}$ a P.

As entrevistas aconteceram em dia/local/horário agendados pelos participantes e buscaram identificar as concepções que possuem sobe a EJA, os principais desafios pedagógicos que vivenciam como docentes da modalidade, o modo que realizam a seleção dos conteúdos, as 
referências teóricas que auxiliam a sua prática, além de questões referentes à formação docente e as mediações que impactam na qualidade e no direito à aprendizagem de jovens, adultos e idosos. A análise do discurso dos sujeitos foi feita a partir do cruzamento das discussões teóricas dos campos da EJA, especialmente Paiva (2014), Barbosa (2016), Oliveira (2009), Machado (2008) e Freire (1996).

O texto se estrutura em três eixos de análise: o primeiro aborda a compreensão que professores possuem acerca da sua formação e como ela reflete na sua prática pedagógica. A segunda reflete as mediações teóricas e práticas que professores identificam como importantes para a qualidade da EJA e o direito de aprendizagem dos estudantes jovens, adultos e idosos. A última parte discute as dificuldades dos docentes em trabalhar com a diversidade presente na modalidade, sobretudo, com a crescente juvenilização da EJA ocorrida nas últimas décadas.

\section{Prática pedagógica e formação docente: a EJA como direito social na concepção dos pro- fessores}

A EJA não se configura apenas reposição da escolaridade aos que não tiveram condições de acesso ou permanência com sucesso à escola na idade considerada adequada, mas a garantia de um direito historicamente negado a milhares de homens e mulheres. Entretanto, como ressalta Gentili (2009), não há garantia do direito quando este ocorre pela metade. Apesar de reconhecer que o avanço obtido por meio da luta contra a alienação, segregação ou negação de oportunidades represente grandes conquistas, o acesso à escola aos segmentos historicamente excluídos dos bancos escolares não se constitui um direito caso o direito à aprendizagem não seja também garantido. Dessa forma, na concepção do autor, mediante os altos índices de pobreza e de desigualdade social na maioria dos países latino-americanos, africanos e asiáticos a universalização das oportunidades de acesso à educação escolar tem se caracterizado em uma "universalização sem direitos”. No Brasil isso é algo que tende a se agravar após a retomada da agenda neoliberal, em 2016, e a aprovação da reforma curricular nos Ensinos Fundamental e Médio, em 2017 e 2018, respectivamente. Daí a importância de refletir os desafios para a garantia plena do direito à educação de pessoas jovens, adultas e idosas.

São muitos os caminhos que possibilitam essa reflexão, seja na área das políticas públicas ou do cotidiano escolar. Entre as funções inerentes ao exercício da docência, Freire (1979) 
destaca a curiosidade dos educandos, já que é ela que os leva a indagar/problematizar a realidade. Cardoso e Passos $(2016$, s/p.) salientam que cabe ao professor "transformar os obstáculos em dados de reflexão para entender os processos educativos, que, como qualquer faceta social, estão relacionados com seu tempo, sua história e seu espaço”. Segundo as autoras, um ambiente acolhedor favorece os processos de ensino e aprendizagem, pois possibilita que os estudantes se sintam confortáveis. Todavia, com base nas narrativas dos professores pesquisados, nem sempre a sala de aula da escola pública carioca e fluminense se configura como um lugar acolhedor em face da escassez de recursos pedagógicos necessários para diversificação das práticas pedagógicas e das precárias condições de infraestrutura dos prédios escolares, muitos deles sem climatização, laboratórios de ciências e informática, e/ou com bibliotecas com acervos adequados à faixa etária do público jovem e adulto atendido. Essa realidade é determinada por múltiplas mediações, entre elas, a má gestão do recurso público, materializada pela corrupção, ausência de políticas para esse fim e o pouco compromisso ético-político de gestores públicos com a EJA, acrescido a pouca sensibilidade estética e comprometimento de alguns docentes com a classe social dos sujeitos atendidos.

Embora não seja um movimento mecânico e linear, a pesquisa tem constatado a relação existente entre o grau de comprometimento do professor e a razão de atuar na modalidade. Se para três docentes (19\%) atuar na EJA sempre foi um desejo, seja por questões pessoais e sociais, para cinco deles (31\%) foi uma "opção de fuga", por considerarem ser "mais fácil, no atual contexto de precarização das escolas e das condições do trabalho docente, trabalhar com jovens $e$ adultos do que trabalhar no ensino regular com crianças e adolescentes" (PROFESSOR L, 2018). Esse pensamento, porém, não é consenso entre os sujeitos pesquisados. Há um grupo de professores que questiona a visão romantizada da EJA difundida no senso comum de que é fácil e tranquilo lecionar na modalidade. O relato de uma professora é bem sintomático quanto a esse aspecto:

Sempre que eu dizia que trabalhava na EJA as pessoas afirmavam que devia ser legal. Isso porque há uma ideia de que na EJA, diferente do ensino fundamental regular, as pessoas estão lá por vontade própria e não por serem obrigadas, então elas teriam mais compromisso e vontade de estudar. Mas isso não é verdade. As razões pelas quais as pessoas voltam para a escola são muitas [...] A EJA é muito romantizada por quem não a conhece de fato. (PROFESSORA M, 2018). 
Por ser ofertada majoritariamente no horário noturno, a EJA tem servido para $56 \%$ dos professores pesquisados como meio de complementação salarial e/ou como forma de acomodar a carga horária da docência com outros cargos/funções que exercem na rede de ensino ou fora dela. Contudo, há também os que são direcionados para a modalidade após aprovação em concurso público sem nunca terem pensado lecionar para jovens, adultos e idosos. Nesse sentido, é bastante significativa a narrativa de uma professora:

Não tinha passado pela minha cabeça, até então, qualquer possibilidade de trabalhar com Educação de Jovens e Adultos. Simplesmente escolhi a escola, e quando me apresentei na escola me disseram que eu iria trabalhar com duas turmas de EJA. Para mim foi uma surpresa, um desafio enorme... quase desisti. (PROFESSORA C, 2018).

O desconhecimento das especificidades da EJA é um fator que pode afastar professores do exercício da docência na modalidade. Esse desconhecimento é ocasionado pelo fato de os cursos de licenciaturas no Brasil privilegiar a formação para atuar com crianças e adolescentes, algo que vem sendo sinalizado há décadas por alguns estudiosos do campo. A pesquisa realizada por Soares (2008) informa que, em 2005, das 612 Instituições de Ensino Superior (IES) brasileiras que ofertavam o curso de Pedagogia e que foram avaliadas pelo Exame Nacional de Cursos apenas 15 ofereciam a habilitação de EJA (2,45\%); dos 1698 cursos existentes na época somente 27 ofertavam essa formação específica (1,59\%). Com base nesses dados verifica-se que pouco se avançou, pois permanece a necessidade de se repensar os currículos dos cursos de licenciatura para que a formação docente inicial trate da modalidade.

Entre as IES públicas do Rio de Janeiro, a Universidade do Estado do Rio de Janeiro (UERJ) foi pioneira em incluir, em 1991, disciplinas obrigatórias que abordam a complexidade dos estudos da EJA no currículo do curso de Licenciatura em Pedagogia (BARBOSA; SOUZA; LINO, 2018). Ou seja, três anos após a Constituição Federal do Brasil (BRASIL, 1988) garantir a educação escolar como direito de todas as pessoas, assegurada inclusive aos que não tiveram acesso a ela na idade própria. No entanto, esse pioneirismo ocorrido na formação do(a) pedagogo(a) não se estendeu as demais licenciaturas, uma vez que as matrizes curriculares não contemplam disciplinas obrigatórias sobre os estudos da EJA, mas apenas como disciplinas eletivas, podendo os estudantes cursá-las ou não. A mesma realidade é vivenciada pelos licenciandos das demais IES públicas do Rio de Janeiro; não obstante esse déficit seja minimizado por meio da extensão acadêmica, de alguns cursos e programas de pós-graduação (lato e stricto sensu) e/ou 
BARBOSA, Carlos Soares; PIRES, Raquel Lopes. Desafios para educação de qualidade e o direito à aprendizagem de jovens, adultos e idosos no tempo presente: o que pensam os professores?

pela formação continuada ofertada por algumas redes de ensino (cada vez mais rara aos professores da EJA).

A formação docente é uma variável importante para a qualidade da educação. A ausência ou pouca oportunidade de estudos sobre a especificidade da EJA durante a formação inicial com jugada com a rara oferta de formação continuada resultam em algumas práticas equivocadas, como a infantilização e/ou adaptação/reprodução da mesma dinâmica de ensino-aprendizagem desenvolvida com crianças e adolescentes no denominado ensino regular (OLIVEIRA, 2009), além de contribuir para a permanência de velhos dilemas vivenciados na modalidade, conforme salientado por Machado (2008):

Como lidar com alunos que chegam cansados, a ponto de dormir durante quase toda aula? Como auxiliar os alunos no seu processo de aprendizagem, com atendimento extra ou atividades complementares, se uma grande parte deles trabalha mais de oito horas diárias, inclusive no final de semana? Como atender as diferenças de interesse geracional, tendo na mesma sala adolescentes e idosos? Como administrar, no processo ensinoaprendizagem, as constantes ausências, em sua maioria justificadas por questões de trabalho, família e doença? Por outro lado, como o professor deve proceder para reconhecer e validar os conhecimentos prévios que os alunos da EJA já trazem? Como trabalhar de forma interdisciplinar se as disciplinas continuam sendo "gavetas" isoladas e com tempo mínimo para algumas áreas de conhecimento? Como o professor, a coordenação da escola e os representantes das secretarias podem ousar na proposição de atendimento diferenciado, que modifique a dinâmica da escola, seja com alternativas de matrícula aberta, avanços progressivos, organização curricular de base paritária, tempo presencial e atividades complementares? (MACHADO, 2008, p. 165/166).

O Parecer n. 11/2000 destaca que cabe "às instituições formadoras o papel de propiciar uma profissionalização e qualificação de docentes dentro de um projeto pedagógico em que as diretrizes considerem os perfis dos destinatários da EJA” (BRASIL, 2000). Todavia, cabe ressaltar, que a qualificação dos profissionais que atuam na EJA implica responsabilidade também das redes de ensino. Assim, entre os sujeitos pesquisados, onze professores (69\%) afirmaram que nunca receberam formação específica para atuar na modalidade, embora seis (37\%) tenham informado que na própria escola ocorrem encontros mensais entre os docentes e a equipe pedagógica para estudos e replanejamento das atividades. A pesquisa realizada por Barbosa (2016) constatou que apesar de a rede municipal do Rio de Janeiro reservar semanalmente aos professores da EJA espaços-tempos para esse fim, se configuram mais como espaço-tempo de divulgação de informações do que de estudos propriamente dito, não promovendo a rotina de reflexão coletiva com auxílio do instrumental teórico. Contudo, a maioria dos professores reconhece a importância 
da formação continuada, ressaltando, porém, que "não pode ser qualquer curso, [...] mas com qualidade; que estimule e dê condições de os profissionais desenvolverem um bom trabalho" (PROFESSORA A, 2018).

Ao avaliarem a sua própria formação, os professores sinalizam que há certos conteúdos teóricos e situações da prática que os cursos de licenciatura deveriam conferir maior atenção, visto que há determinadas situações que os professores se deparam recorrentemente no exercício da profissão, entre elas, a "dificuldade de escrita dos alunos, de compreensão textual, de operações matemáticas simples e a falta de recursos pedagógicos na escola” (PROFESSOR D, 2018). Acrescentam, ainda, os desafios surgidos nas últimas décadas e que não podem ser negligenciados pelas formações, como o aumento significativo de alunos com deficiência e com Necessidades Educacionais Especiais (NEEs) nas turmas de EJA. Embora se careça de maiores estudos sobre as mediações que determinam esse aumento e as mudanças que ele acarreta na dinâmica da sala de aula, algumas inferências podem ser feitas com base no documento Política Nacional de Educação Especial na Perspectiva da Educação Inclusiva (BRASIL, 2008, p. 14-15), que reconhece que "as políticas educacionais implementadas não alcançaram o objetivo de levar a escola comum a assumir o desafio de atender as necessidades educacionais de todos os alunos". Isso ocorre porque a escola ainda desconhece a forma de os estudantes NEEs (sejam crianças, jovens ou adultos) pensarem e interagirem com o mundo, o que gera “certo 'incômodo' no caminhar da escola e em suas práticas diárias" (SOARES, 2014, p. 159).

Para todos os professores pesquisados esse é um desafio a ser enfrentado desde a formação inicial. Para eles, além de garantir disciplinas que abordem a complexidade da EJA no aspecto do currículo, da gestão, das políticas públicas, das práticas pedagógicas, entre outras, é preciso que se garanta também:

Temas relacionados ao desenvolvimento psicomotor e a realidade dos alunos com necessidades educacionais especiais, porque boa parte dos alunos da EJA tem essas necessidades educacionais. É isso o que demonstra sua história de reprovação e insucesso escolar. (PROFESSORA B, 2018).

Como se verifica, os professores pesquisados identificam a formação docente como uma variável importante para a garantia do direito a aprendizagem dos estudantes de todas as idades. A ela somam-se as mediações da prática pedagógica. 


\section{Mediações teóricas e práticas para a qualidade da EJA}

Qualidade é um conceito polissêmico, estando presente nos discursos de pessoas com posicionamentos políticos, ideológicos e de matrizes epistemológicas distintas. Por ser uma construção humana, o conteúdo conferido à qualidade sofre variações de acordo com cada momento histórico e está diretamente vinculado ao projeto de sociedade que os sujeitos defendem. Assim, se para os teóricos da matriz neoliberal qualidade educacional vem associada à produtividade e liberação de fluxo, conjugada à aquisição de competências e habilidades necessárias para formação do trabalhador requerido pela nova configuração do mercado de trabalho; para os teóricos da matriz histórico-crítica a educação socialmente qualificada é a que promove o desenvolvimento de todas as dimensões humanas - do trabalho, da cultura, da ciência, da política -, seguindo os princípios da "escola unitária” de Gramsci (1995), ou da formação freireana, isto é, que possibilite o sujeito a desenvolver suas potencialidades e ser sujeito de sua própria ação, com princípios e práticas que assegurem a dignidade humana, a liberdade e a justiça social.

A pesquisa toma por base o conceito de educação de qualidade presente no documento referência da Conferência Nacional de Educação (CONAE), elaborado pelo Fórum Nacional de Educação, a saber:

Educação de qualidade é aquela que contribui com a formação dos estudantes nos aspectos culturais, antropológicos, econômicos e políticos, para o desempenho de seu papel de cidadão no mundo, tornando-se, assim, uma qualidade referenciada no social. Nesse sentido, o ensino de qualidade está intimamente ligado à transformação da realidade (BRASIL, 2014, p. 52).

A EJA nesses moldes exige o compromisso ético-político de professores, gestores e estudantes, uma vez que sua função social e política vai muito além de ensinar a ler, escrever e fazer cálculos. Tendo sua origem na Educação Popular, a EJA é "mais que um direito: é a chave para o século XXI; é tanto consequência do exercício da cidadania como condição para plena participação na sociedade", conforme expressa na Declaração de Hamburgo (UNESCO, 1997). Seguindo esse lastro a pesquisa tem buscado identificar o significado que professores imprimem à EJA. Os resultados indicam que para a maioria (81\%) trata-se da "retomada dos estudos daqueles que não puderam completá-lo na idade escolar considerada adequada, o que requer do professor o uso de uma metodologia diferenciada” (PROFESSOR P, 2018). Há os que a identifica como meio de 
BARBOSA, Carlos Soares; PIRES, Raquel Lopes. Desafios para educação de qualidade e o direito à aprendizagem de jovens, adultos e idosos no tempo presente: o que pensam os professores?

integração social, se reportando aos estudantes como "excluídos” de um conjunto de direitos. Afirmam que "a EJA é um direito de extrema importância, pois trabalha com o cidadão ou o não cidadão do presente” (PROFESSORA F, 2018).

De modo geral as narrativas demonstram que a concepção da educação compensatória ainda é bastante forte no imaginário coletivo dos professores pesquisados, não obstante Paulo Freire seja indicado como a principal referência do fazer pedagógico, como se observa no discurso de uma professora:

Mesmo sendo clichê acho que não dá para fugir de Paulo Freire quando se trata da EJA. Não que eu tenha usado leituras de Paulo Freire para embasar alguma metodologia, mas ele faz pensar na educação de uma forma diferente. E a EJA é uma educação diferente. Trabalhar com jovens e adultos deixa mais evidente que o aluno tem conhecimentos. (PROFESSORA E, 2018)

A despeito da importância de Paulo Freire, a pesquisa tem constatado que os novos estudos sobre a EJA têm sido pouco apropriados pelos professores, assim como o conhecimento de legislações e documentos orientadores de políticas que normatizam e interferem no cotidiano da escola, a exemplo do Parecer n. 11/2000 que instituiu as Diretrizes Curriculares da EJA (BRASIL, 2000). No entanto, $50 \%$ dos professores consideram importante o estudo e a compreensão de algumas legislações, tendo em vista que elas buscam normatizar, direta ou indiretamente, a prática docente, podendo contribuir para que

a EJA seja tratada de forma especifica e não como mera adaptação do ensino regular [...] travei uma briga na escola exigindo que os conselhos de classe (COC) fossem específicos da EJA. Como os professores do segundo segmento complementam no noturno, eles acabam fazendo o COC num turno só, mas justamente pela especificidade da EJA que deve ser a parte. (PROFESSORA A, 2018)

A defesa de um espaço-tempo próprio para refletir as questões da EJA justifica-se pelo reconhecimento das especificidades e complexidades da modalidade, seja em termos de disciplina, assiduidade e ritmos de aprendizagem dos estudantes, seja em termos de metodologia e seleção dos conteúdos por parte dos docentes. No entanto, esses não foram aspectos destacados espontaneamente pelos professores. Dos 16 pesquisados, apenas seis destacaram que a seleção dos conteúdos deve merecer maior atenção na EJA por duas razões: evitar que a organização dos conteúdos e os modos privilegiados da abordagem sigam as propostas desenvolvidas com crianças e adolescentes, e por entender que a metodologia e os conteúdos devem auxiliar os educandos jovens, adultos e idosos a resolverem os desafios e demandas da vida cotidiana. Ademais, os 
BARBOSA, Carlos Soares; PIRES, Raquel Lopes. Desafios para educação de qualidade e o direito à aprendizagem de jovens, adultos e idosos no tempo presente: o que pensam os professores?

estudos já ressaltaram que se o educando da EJA não percebe o ensino trabalhado no espaço escolar "como importante para seu desenvolvimento, ele não compreenderá a razão de ter que aprender certos conteúdos e, não os compreendendo, tenderá a achá-los pouco atrativo e, consequentemente, pode abandonar a escola" (MACHADO; RODRIGUES, 2014, p. 388). Assim, na concepção de uma professora, como "os alunos da EJA têm mais dificuldades em acompanhar o conteúdo, é preciso que o conteúdo tenha sentido, tenha significado social, e seja desenvolvido para além da metodologia tradicional baseada unicamente na oralidade” (PROFESSORA C, 2018). Ou seja, "cabe ao professor selecionar o que realmente é interessante para os alunos" (PROFESSORA B, 2018).

Considerando que entre os professores pesquisados há os que atuam na rede estadual na etapa do Ensino Médio e outros que atuam na etapa de Ensino Fundamental em redes municipais distintas, observa-se que algumas redes elaboram um "currículo mínimo" para a modalidade, enquanto outras disponibilizam as "orientações curriculares" no site da secretaria de educação. Há, inclusive, as que concedem total liberdade para que professores construam seu projeto pedagógico-curricular, o que pode significar, a princípio, algo positivo na perspectiva da autonomia docente. Entretanto, o excesso de autonomia conferida aos docentes sem que haja o mínimo de orientação acaba por gerar insegurança nos profissionais com pouca experiência na modalidade, além de corroborar para a persistência da compreensão da EJA como território provisório aberto à improvisação e um campo educativo de pouco prestígio e baixo grau de formalização (DI PIERRO, 2005). O depoimento de uma professora retrata bem essa realidade:

Na EJA eu praticamente fazia o que queria, o que tem seu lado bom. Bom, porque eu tinha autonomia para conduzir a disciplina. Afinal, quem melhor que o professor para decidir o que será dado ou não? É ele quem conhece a turma. Mas, por outro lado, era ruim. Me sentia bastante perdida no começo; tinha semanas que eu não sabia mais o que fazer. Por ser recém-formada, não estava preparada ainda para essa autonomia, não sabia o que e como trabalhar. (PROFESSOR D, 2018).

De acordo com o Parecer no 11/2000 a EJA é a porta de entrada para "o exercício da cidadania na sociedade contemporânea, que vai se impondo cada vez mais nestes tempos de grandes mudanças e inovações nos processos produtivos" (BRASIL, 2000, p. 10). Ressalta que:

A reentrada no sistema educacional dos que tiveram uma interrupção forçada seja pela repetência ou pela evasão, seja pelas desiguais oportunidades de permanência ou outras condições adversas, deve ser saudada como uma reparação corretiva, ainda que tardia, de estruturas arcaicas, possibilitando aos indivíduos novas inserções no mundo do trabalho, na vida social, nos espaços da estética e na abertura dos canais de participação (BRASIL, 2000, p. 9). 
BARBOSA, Carlos Soares; PIRES, Raquel Lopes. Desafios para educação de qualidade e o direito à aprendizagem de jovens, adultos e idosos no tempo presente: o que pensam os professores?

Apesar da importância político-social para a construção de uma sociedade mais justa e democrática, a EJA é pouco valorizada pelos gestores e pelas políticas públicas, o que contribui para a baixa qualidade na modalidade. A esse respeito, um dos professores cita Darcy Ribeiro e afirma:

A crise na educação não é uma crise, é um projeto, por isso nem o ensino regular é de qualidade. Na EJA a situação é muito mais precária. O quadro de funcionários é reduzido, material é sempre por último, pois a prioridade é o ensino regular, a carga horária é menor, aliada a frequência irregular de muitos alunos. (PROFESSOR K, 2018).

Em meio a tantas dificuldades evidenciadas no discurso do professor, Colavitto e Arruda (2014) salientam que os problemas para efetivar a EJA com qualidade estão mais relacionados aos métodos, a qualificação de professores e a carência de materiais adequados, dificultando os estudantes a acompanharem os estudos e a construírem aprendizagens significativas. A permanência do paradigma de suplência e da educação compensatória em que os conteúdos são trabalhados aligeiradamente também criam obstáculos para a qualidade social da EJA. Corrobora para isso, na concepção de sete professores (44\%), o objetivo da certificação por parte da maioria dos estudantes, ainda que seja uma "certificação vazia”, isto é, destituída de conhecimentos necessários para prosseguimento dos estudos, conforme ressalta uma professora:

Não vejo qualidade na EJA. Não acredito que a proposta da EJA vise qualidade. Minhas turmas são uma espécie de supletivo. Eles terminam uma série em um semestre. Tudo muito corrido. As orientações recebidas sempre são no sentido de não exigir do aluno. Tudo tem que ser feito na sala de aula, pois mesmo os alunos que não trabalham não fazem as atividades extraclasses. Isso pressupõe que não é a qualidade do ensino que está sendo visada, não é o percurso do aluno na escola, o que importa é a permanência e a conclusão. (PROFESSORA E, 2018).

O binômio aceleração de estudos e qualidade de ensino constitui um contraponto discutido há anos na modalidade, tanto por professores quanto por pesquisadores e gestores públicos. Foi em nome do (suposto) aumento da qualidade de ensino que a Secretaria de Estado de Educação do Rio de Janeiro, em 2013, implementou uma série de reformas na EJA na etapa do Ensino Médio. Além da elaboração de livro didático próprio e formação ofertada aos professores, promoveu a reorganização curricular e aumentou a carga horária e a duração do curso, de um ano e meio para dois anos, no total de quatro módulos. Embora a reorganização curricular seja um passo importante para a qualidade educacional, ela não é capaz de assegurá-la caso não venha conjugada com outras ações, entre as quais: valorização salarial dos profissionais, investimento na 
formação docente inicial, ampliação das ofertas de formação continuada, melhoria nas condições de infraestrutura das escolas, recursos pedagógicos adequados que visem atender as necessidades educacionais dos estudantes, metodologias que estimulem à curiosidade epistemológica, o pensamento crítico, à autonomia e o respeito às diferenças. Afora as mediações de natureza socioeconômicos e socioculturais que interferem na baixa autoestima dos jovens e adultos, exigindo que a EJA seja pensada pela perspectiva da intersetorialidade, posto que não é capaz de dar conta sozinha das necessidades econômicas e psicossociais do público atendido.

A gestão é outra mediação destacada pelos professores pesquisados para a qualidade e o desenvolvimento do trabalho docente, daí a necessidade de "o gestor precisar ter experiência na EJA, compreender o público atendido e usar uma metodologia de gestão própria para a modalidade” (PROFESSOR H, 2018). Na concepção de 50\% dos professores pesquisados, a gestão escolar comprometida com a modalidade pode minimizar algumas práticas que reforçam a destituição do direito à aprendizagem de jovens e adultos, como, por exemplo, impedir o acesso dos estudantes do noturno a determinadas dependências da escola, não promover atividades extraclasses e/ou não criar condições para potencializar no espaço escolar as manifestações culturais dos sujeitos da EJA.

Na concepção dos professores, portanto, não são poucos os desafios para a promoção e o reconhecimento da EJA como campo educativo de prestígio social, o que se intensifica no atual contexto de estandartização das avaliações institucionais e a corrida das redes de ensino e das escolas para atingir as metas projetadas pelo Índice de Desempenho da Educação Básica (IDEB). E pelo fato de os resultados da modalidade não participarem do cômputo do IDEB não há muito interesse dos gestores públicos em investir na qualidade da EJA, sendo tratada como estratégia para "maquiar" os resultados e melhorar o fluxo escolar. Desse modo, junto aos programas de aceleração de estudos para fins de correção de fluxo, a transferência para a EJA dos jovens com histórico de muitas reprovações no ensino regular tem sido orientada pelas secretarias de educação e pelos gestores escolares, o que não contribui para a consolidação da modalidade como política pública de Estado, além de reforçar a ideia da EJA como um atendimento provisório, como salientam Machado e Rodrigues (2014). Onze professores pesquisados (68\%) questionam essa função utilitária e uma delas argumenta da seguinte forma: 
BARBOSA, Carlos Soares; PIRES, Raquel Lopes. Desafios para educação de qualidade e o direito à aprendizagem de jovens, adultos e idosos no tempo presente: o que pensam os professores?

A todo tempo os professores da escola são induzidos a aprovar os alunos, mesmo que eles apresentem dificuldades nos conteúdos trabalhados [...], alegando que as reprovações prejudicam as avaliações dos sistemas de ensino, que prejudica o fluxo escolar e etc. O que é mais fácil: descobrir as causas do fracasso escolar e atender as necessidades dos alunos, ou jogá-los na EJA? A EJA é vista como uma solução para os problemas do Ensino Fundamental e Médio. (PROFESSORA E, 2018).

O processo de juvenilização da EJA, portanto, não é explicado somente pelo ingresso precoce dos jovens das camadas populares no mercado de trabalho, mas também pelo processo de transferência compulsória para a EJA dos alunos considerados “indisciplinados" e/ou que apresentam dificuldades de aprendizagens. Assim, no atual contexto da pedagogia dos resultados, a performance estatística sobrepõe-se ao desenvolvimento humano e aos valores éticos e de cidadania, ocasionando a entrada cada vez mais precoce de jovens na modalidade.

\section{Juvenilização da EJA e as consequências na prática pedagógica: reflexões (im)pertinentes}

A crescente juvenilização na EJA ocasiona muitas problematizações entre os docentes. Ao buscarem explicar as mediações que têm determinado o aumento da quantidade de jovens nas turmas da EJA nos últimos anos os professores fazem uso, ainda que inconscientemente, de preconceitos dirigidos as juventudes e muito presente no senso comum. Afirmam que:

Esses alunos mais jovens, como não querem nada no regular, vão para a EJA achando que vai ser moleza, mas não é moleza, embora seja mais fácil para quem quer estudar. (PROFESSORA G, 2018)

A maioria dos jovens ou já trabalha, muitos deles na informalidade, ou são oriundos de programas de aceleração. E como eles não conseguem acompanhar o ensino regular, acabam na EJA como se fosse um ensino mais fraco, por ser mais compacto e objetivo... é isso que os alunos pensam. (PROFESSOR D, 2018)

Segundo os professores, o corpo discente é constituído por pessoas na faixa etária de 16 a 70 anos. A diversidade geracional não é concebida como algo positivo pela maioria dos docentes, estabelecendo comparações entre o comportamento dos segmentos juvenil, adultos e idosos, pouco atentos ao fato de que cada etapa da vida possui especificidades próprias.

O aluno mais jovem da EJA geralmente não quer estudar, ao contrário dos alunos que têm certa idade, que vêm com uma bagagem maravilhosa, participam muito da aula e querem aprender. Trazem as experiências de vida, começam associar o conteúdo que estamos dando e isso é muito bonito. Mas o adolescente acaba os constrangendo, porque fica com um ar de deboche. Isso para mim é o aspecto negativo da EJA. (PROFESSOR H, 2018) 
BARBOSA, Carlos Soares; PIRES, Raquel Lopes. Desafios para educação de qualidade e o direito à aprendizagem de jovens, adultos e idosos no tempo presente: o que pensam os professores?

As narrativas dos professores demonstram as dificuldades que possuem em dialogar com a cultura juvenil e, por conseguinte, compreenderem suas demandas atuais e os modos de estarem e compreenderem o mundo. Apesar da diversidade, os jovens da EJA possuem em comum a marca da pobreza, sendo eles majoritariamente moradores de periferias, favelas e bairros pobres. Conforme ressalta Barbosa (2018, p. 288-209), jovens que na atual "sociedade da descartabilidade" vivem o "curto aqui e agora" em face do desemprego estrutural, do crescimento da violência urbana e da precarização das relações de trabalho. Contudo, de acordo com o autor, a despeito das transformações ocorridas na subjetividade dos jovens determinadas pela reestruturação produtiva e pelas mudanças no mundo do trabalho, alguns professores continuam a exigir um modelo ideal de alunos e de jovens que não corresponde à juventude do tempo presente. Nesse sentido, a indisciplina e o desinteresse de alguns pelo universo escolar também podem ser explicados pela invisibilidade a que são tratados na/pela escola, incidindo em um histórico de reprovação no denominado ensino regular. Em decorrência do não sucesso escolar muitos optam pela transferência para a EJA por concebê-la como meio mais fácil de dar prosseguimento a trajetória escolar. Sendo assim, para um dos professores pesquisados,

os alunos jovens da EJA no Ensino Médio são aqueles que ficaram reprovados várias vezes no ensino regular e vão para a EJA para agilizar a escolarização, para pegarem o certificado que o mercado de trabalho exige, por ser, na visão deles, um curso mais fraco e mais fácil de passar de série [...] (PROFESSOR K, 2018).

Outro aspecto que o processo de juvenilização da EJA provoca é certo tensionamento acerca da diversidade e do atendimento das expectativas dos sujeitos, uma vez que possuem histórias de vida, interesses e ritmos de aprendizagens distintos dos estudantes adultos e idosos. Assim, para nove professores (56\%) o maior desafio em atuar na EJA consiste na diversidade do público atendido, especialmente em relação à diversidade geracional, como bem expõe o depoimento de uma delas:

Achava que eu ia encontrar velhinhos fofos com vontade de aprender, mas encontrei jovens que não se enquadraram no ensino fundamental regular e foram convidados a ir para a EJA como forma de regularizar o fluxo, pois eles reprovavam muito e tinham problemas de indisciplina. Há também os alunos de mais idade, que vão para a escola apenas para socializar; terem com quem conversar. Isso se constitui num grande desafio, pois os professores têm que lidar com uma diversidade enorme em sala de aula, desde a questão da idade até a aprendizagem. É claro que existe diversidade no ensino fundamental, mas na EJA é bem mais complexo. Dei aula para uma mãe e três filhos na mesma sala. Tive alunos que tinham muitas dificuldades, pois estavam muito tempo fora da escola. Tive turmas em que os mais velhos eram os melhores alunos. Em outras eram os que mais me causavam problemas. Enfim, não dá para generalizar as turmas da EJA. Cada turma é única, com seus desafios e alegrias. (PROFESSORA E, 2018). 
Além do aspecto geracional há também a diversidade regional, étnico-racial, sexualidade, de concepção de mundo, credos e ritmos de aprendizagens, o que reivindica do professor o desenvolvimento de um trabalho diversificado, significativo e que dialogue com a cultua juvenil. Mas como nem todos se sentem seguros diante de expressiva diversidade, alguns acabam desistindo de atuar na modalidade, como bem expõe o relato de uma professora:

Para trabalhar com a EJA a gente precisa se desfazer de muitas ideias que temos, de como deve ser a educação. Eu ainda carrego muito dessa idealização e acho que por isso eu não gostei de trabalhar na EJA. Apesar de não ter gostado, sei o quanto foi e é importante esse trabalho para o meu crescimento profissional. (PROFESSOR P, 2018).

Nesse sentido, a pesquisa tem buscado identificar as metodologias e os recursos didáticos que os professores têm utilizado para atendimento da diversidade. Os dados indicam que os poucos recursos tecnológicos acessíveis aos professores e aos estudantes da EJA dificultam a aprendizagem dinâmica e significativa no chão da escola. Para contornar essa situação os professores utilizam algumas estratégias, como adequar a linguagem, realizar trabalhos em grupos e usar textos com temáticas que despertem o interesse da maioria.

Aliás, manter o interesse dos estudantes e estimulá-los a não desistir de seus objetivos e sonhos são alguns dos desafios reportados pelos professores, mediante as precárias condições de reprodução da existência da maioria dos estudantes e das exaustivas jornadas de trabalho. Realidade esta que, resguardadas as devidas proporções, também é vivenciada pelos professores da EJA, já que para muitos deles o horário noturno constitui na tripla jornada de trabalho.

\section{Considerações finais}

Conforme destacado nesse texto, a diversidade da/na EJA não circunscreve apenas aos sujeitos atendidos; mas perpassa também pelas distintas concepções dos professores sobre a EJA e sobre sua função política e social. Por um lado, a romantização da EJA presente no discurso dos docentes que a concebe na perspectiva da suplência, da educação compensatória e, consequentemente, como uma formação que exige pouco do professor e do estudante tende a secundarizar a expressiva diversidade do público atendido e as distintas abordagens metodológicas que ela deve provocar. Por outro, os professores que a compreendem como direito humano e social e orientam sua ação pedagógica na perspectiva da inclusão e da prática democrática enfatizam a 
complexidade da sala de aula e os desafios para garantir a efetiva qualidade social da EJA e o direito à aprendizagem de jovens, adultos e idosos. Desse modo, na concepção dos professores, esses desafios são de natureza econômica, política, social e pedagógica, entre elas: precarização das condições objetivas/subjetivas de produção e reprodução da existência dos educandos, que incide na frequência irregular a escola e na ausência de tempo para os estudos fora do horário escolar; descompromisso ético-político de alguns professores e gestores com a modalidade, concebendo-a como um favor em detrimento do direito; pouca atenção conferida à formação docente (inicial e continuada), o que dificulta a construção de currículos e de projetos pedagógicos que constituam a realidade histórico-cultural, as expectativas e os interesses dos educandos como ponto de partida e de chegada do percurso formativo; além dos baixos investimentos financeiros e a ausência de políticas públicas que criem as condições necessárias para o desenvolvimento de metodologias diferenciadas voltadas a atender a diversidade cognitiva e cultural dos sujeitos.

No tempo presente, os desafios sinalizados tendem a se agravar mediante o ataque aos direitos vivenciados pelos profissionais das redes municipal e estadual do Rio de Janeiro e do município de Duque de Caxias em termos de correção salarial, concessão de licenças e formação continuada em nome da (suposta) crise financeira.

Contudo, o objetivo de identificar as concepções dos professores sobre as mediações que dificultam a efetivação do direito à aprendizagem de pessoas jovens, adultas e idosas não tem a intenção de apenas apontar os problemas/desafios, mas provocar novas estratégias de diferentes matrizes que venham a garantir o direito à educação de qualidade social para todas as pessoas. Direito este que não se restringe em facilitar o acesso ao certificado, mas que promova o direito a aprendizagem, no entendimento de que a efetivação de todo direito deve ser plena e não pela metade.

\section{Referências}

BARBOSA, Carlos Soares. Limites e possibilidades da contribuição do PIBID na inicial e continuada de professores da educação de jovens e adultos. Educere et Educare Revista de Educação, Cascavel, v. 11, n. 22, p. 340-352, jul./dez. 2016.

BARBOSA, Carlos Soares. Juventudes e produção de subjetividades no contexto de acumulação flexível do capital. Interfaces da Educação, Parnaíba, v. 9, n. 27, p. 274-293, set./dez. 2018. 
BARBOSA, Carlos Soares; PIRES, Raquel Lopes. Desafios para educação de qualidade e o direito à aprendizagem de jovens, adultos e idosos no tempo presente: o que pensam os professores?

BARBOSA, Carlos Soares, SOUZA; José Carlos Lima, LINO, Lucília Augusto. Formação de professores para a educação de jovens e adultos: desafios, propostas curriculares e considerações sobre o direito à educação. Revista Educação e Cultura Contemporânea, Rio de Janeiro, v. 15, n. 41, p. 343-362, 2018.

BRASIL. Conferência Nacional de Educação (CONAE): documento - referência/[elaborado pelo] Fórum Nacional de Educação. Brasília: MEC, 2014.

BRASIL. Política Nacional de Educação Especial na Perspectiva da Educação Inclusiva. Brasília: MEC, jan. 2008. Disponível em: http://portal.mec.gov.br/arquivos/pdf/politicaeducespecial.pdf. Acesso em: 25 nov. 2017.

BRASIL. Diretrizes Curriculares Nacionais para a Educação de Jovens e Adultos. Parecer 11/2000. Brasília: CBE, 2000. Disponível em:

http://confinteabrasilmais6.mec.gov.br/images/documentos/parecer_CNE_CEB_11_2000.pdf. Acesso em: 21 out. 2018.

BRASIL. Constituição da República Federativa do Brasil de 1988. Brasília: Senado Federal: Centro Gráfico, 1988. Disponível em: http://www.planalto.gov.br/ccivil 03/constituicao/constituicaocompilado.htm. Acesso em: 21 out. 2018.

CARDOSO, Marcélia Amorim; PASSOS, Gisele de Andrade Louvem dos. Reflexões sobre a educação de jovens e adultos e a formação docente. Revista Educação Pública, Rio de Janeiro, v. 16, n. 25, p. 1-7, dez. 2016. Disponível em: http://educacaopublica.cederj.edu.br/revista/artigos/reflexoes-sobre-aeducacao-de-jovens-e-adultos-e-a-formacao-docente. Acesso em: 17 out. 2018.

COLAVITTO, Nathalia Bedran; ARRUDA, Aparecida Luvizotto Medina Martins. Educação de jovens e adultos (EJA): a importância da alfabetização. Revista Eletrônica Saberes da Educação, São Roque v. 5, n. 1, p. 1-28, 2014. Disponível em:

http://docs.uninove.br/arte/fac/publicacoes_pdf/educacao/v5 n1 2014/Nathalia.pdf. Acesso em: 21 out. 2018.

DI PIERRO, Maria Clara. Notas sobre a redefinição da identidade e das políticas públicas de educação de jovens e adultos no Brasil. Educação e Sociedade, Campinas, v. 26, n. 92, p. 1115-1139, 2005.

FREIRE, Paulo. Educação como prática da liberdade. 17. ed. Rio de Janeiro: Paz e Terra, 1979.

FREIRE, Paulo. Pedagogia da Autonomia: saberes necessários à pratica educativa. 31. ed. São Paulo: Paz e Terra, 1996.

GENTILI, Pablo. O direito à educação e as dinâmicas de exclusão na América Latina. Educação e Sociedade, Campinas, v. 30, n. 109, p. 1059-1079, set./dez. 2009.

GRAMSCI, A. Os Intelectuais orgânicos e a organização da cultura. 9. ed. Rio de Janeiro: Civilização Brasileira, 1995.

IBGE. Pesquisa Nacional por Amostra de Domicílios (PNAD) 2018. Disponível em: https://biblioteca.ibge.gov.br/visualizacao/livros/liv101576_informativo.pdf Acesso em: 12 dez. 2018.

MACHADO, Maria Margarida. Formação de professores para a EJA: uma perspectiva de mudanças. Revista. Revista Retratos da Escola, Brasília, v. 2, n.2-3, jan./ dez., 2008.

MACHADO, Maria Margarida; RODRIGUES, Maria Emília de Castro. A EJA na próxima década e a prática pedagógica docente. Revista Retratos da Escola, Brasília, v. 8, n. 15, jul./ dez., 2014.

OLIVEIRA, Inês Barbosa de. Organização curricular e práticas pedagógicas na EJA: algumas reflexões. In: PAIVA, J.; OLIVEIRA, I. B. (orgs.). Educação de jovens e adultos. Pe trópolis, RJ: DP et Alii, 2009. p. 96-107. 
PAIVA, Jane. Os desafios da educação no tempo presente. O lugar da EJA: de que lugar estamos falando? In: COSTA, R. P.; VIANNA, V. M. Entrelaçando olhares por uma educação planetária. Rio de Janeiro: Caetés, 2014. p. 77-106.

SOARES, Andrea. Alunos PNEEs na EJA: sujeitos de direitos e complexidade. In: COSTA, R. P.; VIANNA, V. M. Entrelaçando olhares por uma educação planetária. 1. ed. Rio de Janeiro: Caetés, p. 153165, 2014.

SOARES, Leôncio. O educador de jovens e sua formação. Educação em Revista, Belo Horizonte, n. 47, p. 83-100, jun. 2008.

UNESCO, CONFINTEA V. Declaração de Hamburgo. In: CONFERÊNCIA INTERNACIONAL DE EDUCAÇÃO DE ADULTOS, 5., 1997, Hamburgo. Alemanha: Hamburgo. Anais [...]. Alemanha: Hamburgo 1997. Disponível em: https://unesdoc.unesco.org/ark:/48223/pf0000116114_por. Acesso em: 12 dez. 2018.

VENTURA, Jaqueline; RUMMERT, Sônia. Considerações político-pedagógicas sobre as especificidades da educação de jovens e adultos trabalhadores. In: SOUZA, J. dos S.; SALES, S. R. (orgs.). Educação de jovens e adultos: políticas e práticas educativas, Rio de janeiro: Nau Editora, EDUE-UFRRJ, 2011. p. 6786. 